\title{
Epidemiology of Hypertensive State among Chinese Migrants: Effects of Unaffordable Medical Care
}

\author{
Ming Guan (iD) ${ }^{1,2}$ \\ ${ }^{1}$ Family Issues Center, Xuchang University, Road Bayi 88, Xuchang, Henan, China \\ ${ }^{2}$ School of Business, Xuchang University, Road Bayi 88, Xuchang, Henan, China \\ Correspondence should be addressed to Ming Guan; gming0604@163.com
}

Received 13 February 2018; Revised 6 April 2018; Accepted 16 April 2018; Published 29 May 2018

Academic Editor: Tomohiro Katsuya

Copyright (C) 2018 Ming Guan. This is an open access article distributed under the Creative Commons Attribution License, which permits unrestricted use, distribution, and reproduction in any medium, provided the original work is properly cited.

\begin{abstract}
Hypertension is a major risk factor for heart disease and stroke. Affordability of medical care affects hypertension prevention, treatment, and control, but limited information is available for Chinese migrants with hypertensive state. Using Longitudinal Survey on Rural Urban Migration in China 2009 data, 2468 Chinese migrants reported hypertensive status. On the basis of comparison between medical payment and job income, participants were categorized as unaffordable and affordable. Thus, unaffordable expenses and unaffordable services were defined based on a public available survey. The descriptive statistics showed that $24.96 \%$ were at risk of prehypertension and mild-moderate-severe hypertension among 2468 Chinese migrants from 15 cities. Small part of the sample was not affordable to pay medical expenses and services. There were significant differences of hypertensive states between gender, marital status, regular smoker, and economic unaffordability. Multiple logistic regressions indicated that economic unaffordability had associations with abnormal weight, poor health assessment, and unhealthy hypertensive status. The alarming results may necessitate targeted interventions, even among people with good health status.
\end{abstract}

\section{Introduction}

Hypertension was an important public health burden in China, and control of hypertension was still suboptimal [1]. The trend of an increase in prevalence of hypertension in China was striking in young people and rural populations [2]. Hypertension prevalence in north China was 9.1\% (95\% CI: 4.1-14.1), which was higher than south China [3]. The treatment and control status of incident hypertension, while improved, remained very poor [4]. Rates of awareness and treatment of hypertension remained low and blood pressure was poorly controlled [5]. There was an urgent need for public health strategies with more emphasis on improvement of primary healthcare in China [6]. Inadequate counseling, lack of understanding on the disease, difficulties in accessing specialist care, and poor medication adherence were the barriers to optimal blood pressure control [7]. In addition, many cases of hypertension were going undetected and untreated under the effective health system in China [8]. Inadequate health insurance coverage for the high hypertension-risk migrants remained a challenge for the Chinese health reform [9].
Clinically, hypertension transits from normal blood pressure (normal pressure) to prehypertension, moderate hypertension, and severe hypertension. Normal pressure was defined as $90 \mathrm{~mm} \mathrm{Hg}$ < systolic blood pressure $<120 \mathrm{~mm} \mathrm{Hg}$ and $60 \mathrm{~mm} \mathrm{Hg}<$ diastolic blood pressure $<80 \mathrm{~mm} \mathrm{Hg} \mathrm{[10].}$ Prehypertension referred to a systemic BP of $120-139 \mathrm{~mm} \mathrm{Hg}$ systolic and/or 80-89 $\mathrm{mm} \mathrm{Hg}$ diastolic [11]. Prehypertension was often associated with other cardiovascular risk factors and independently increases the risk of hypertension and subsequent cardiovascular events [12]. Mild-and-moderate hypertension also was defined (mean sitting systolic $\mathrm{BP} /$ mean sitting diastolic BP, mild: 140-179/90-109 mmHg) [13]. Thus, severe hypertension was defined as (mean sitting systolic $\mathrm{BP} /$ mean sitting diastolic BP, severe: $180-/ 110-\mathrm{mmHg}$ ).

The primary care was effective in managing hypertension irrespective of management and operation models in urban China [14]. The migrants, the poor, and the vulnerable remained in the edge of the health insurance system [15]. Thus, subjects from rural migrants in urban China can be considered as a specifically medical and clinical targeted group. 
The objective of this study was to assess the relationship between healthcare affordability and its association with change of hypertensive state among the Chinese migrants. Hypertensive state was defined under the combination of systolic pressure and diastolic pressure. Multiple logistic regressions were conducted to compute association of economic unaffordability with BMI, health assessment, and hypertensive states.

\section{Methods}

2.1. Data Source. This study used data from the Longitudinal Survey on Rural Urban Migration in China (RUMiC) organized by Professor Xin Meng at Australian National University. Detailed information is available at https://datasets.iza.org/. The core component was conducted in 15 Chinese cities (Guangzhou, Dongguan, Shenzhen, Zhengzhou, Luoyang, Hefei, Bengbu, Chongqing, Shanghai, Nanjing, Wuxi, Hangzhou, Ningbo, Wuhan, and Chengdu).

2.2. Main Variables. Unaffordability was defined based on the following questions: (a) Expenses: "how much were your total medical expenses on the disease in the last three months?" (b) Services: "what was the total amount of your cash expenditure on medical services in 2007?” (c) Income: "what is your average monthly income from current primary job?" Thus, two variables, "unaffordable expenses" and "unaffordable services," were constructed after income minus the two types of expenditure, respectively. Subsequently, "unaffordable expenses" and "unaffordable services" were also dichotomized into 1 and 0 , when they were above 0 and equal to or below 0 . Negative values were defined as unaffordability, while zero and positive values were defined as affordability.

Sociodemographic characteristics collected were age (9-25, 26-40, and $\geq 41$ years), sex, marital status (married and other), current work status (employed and other), and BMI. Obesity was defined using BMI according to the Chinese criteria: underweight (less than $18.5 \mathrm{~kg} / \mathrm{m}^{2}$ ), normal $\left(18.5-23.9 \mathrm{~kg} / \mathrm{m}^{2}\right)$, overweight $\left(24.0-27.9 \mathrm{~kg} / \mathrm{m}^{2}\right)$, and obese (equal to or more than $28.0 \mathrm{~kg} / \mathrm{m}^{2}$ ) [16].

2.3. Statistical Analysis. The distributions of normal pressure, prehypertension, and mild-moderate-severe (MMS) hypertension were assessed by sociodemographic characteristics. Using unaffordable expenses and services as covariates, logistic regression models were mainly used to assess the associations of hypertensive state, while adjusting for age, sex, marital status, current work status, and education. All analyses accounted for the RUMiC complex sample design by using STATA 14.0 for Windows (STATA Corp, College Station, TX, USA).

\section{Results}

Overall, $63.25 \%$ of the sample was males among 2468 individuals aged $\geq 18$ years included in the study. The participants had the mean age of 32.37 years (95\% CI 31.26-33.46, range $18-72$ years), with mean systolic blood pressure of $119.22 \mathrm{~mm} \mathrm{Hg}$
(95\% CI 118.78-119.66, range $90.01-191.67 \mathrm{~mm} \mathrm{Hg}$ ), and mean diastolic blood pressure of $75.90 \mathrm{~mm} \mathrm{Hg}$ (95\% CI 75.58-76.22, range $60.02-124.67 \mathrm{~mm} \mathrm{Hg}$ ).

In Table 1 , there were significant differences of hypertensive state among age, gender, marital status, regular smoker, unaffordable expenses, and unaffordable services. Among the 2468 participants, $19.85 \%$ was risk of prehypertension, and $5.11 \%$ was risk of MMS hypertension. $1.30 \%$ was unaffordable to pay medical expenses. $8.47 \%$ was unaffordable to pay medical services. The migrants who could not afford medical services were more than migrants who could not afford medical expenses.

In Table 2, unaffordable services were significantly associated with being underweight, overweight, and obese. But, the odds ratios were below 1 . In Table 3, unaffordable expenses were significantly associated with average and poor health assessment. Unaffordable services were associated with excellent, good, average, poor, and very poor health assessment. But, the odds ratios were below 1. This suggested that increase in unaffordable services would produce decrease in dimensions in health assessment.

In Table 4, age range $26-40$ was associated with normal pressure (AOR: 1.380; 95 CI: 1.150-1.657), prehypertension (AOR: 0.598; $95 \mathrm{CI}: 0.494-0.723$ ), and MMS hypertension (AOR: 0.097; 95 CI: 0.069-0.137). Age $\geq 41$ was associated with prehypertension (AOR: 0.560; $95 \mathrm{CI}: 0.428-0.732$ ) and MMS hypertension (AOR: 0.418; 95 CI: 0.310-0.565). This suggested that young migrants would be more likely to be in risk of hypertension than old migrants did. Female was associated with normal pressure (AOR: 3.823; 95 CI: 3.059-4.777), prehypertension (AOR: 0.263; $95 \mathrm{CI}$ : 0.207-0.335), and MMS hypertension (AOR: 0.206; 95 CI: 0.140-0.301). Never married status was associated with normal pressure (AOR: 3.519; 95 CI: 2.865-4.323), prehypertension (AOR: 0.266; 95 CI: 0.214-0.330), and MMS hypertension (AOR: 0.034; 95 CI: 0.019-0.060). Regular smoker was associated with normal pressure (AOR: 1.258; $95 \mathrm{CI}$ : 1.012-1.564), prehypertension (AOR: 0.780; 95 CI: 0.621-0.978), and MMS hypertension (AOR: 0.474; $95 \mathrm{CI}$ : 0.331-0.678). Unaffordable services were associated with normal pressure (AOR: 0.659; 95 CI: 0.462-0.940) and prehypertension (AOR: 1.672; 95 CI: 1.153-2.425). This suggested that female, never married, regular smokers with higher age were not likely to be at risk of prehypertension and MMS hypertension. Persons with unaffordable services were likely to be at risk of prehypertension. Due to the smallest odds ratio in the table, never married subjects face the highest risk of hypertension.

\section{Discussion}

The findings of this study indicate that hypertensive state has been very prevalent in Chinese migrants. Part of Chinese migrants suffering from hypertension was accompanied by unaffordable expenses and services. With respect to high medical fees, affordable coverage could not be available to each migrant. Even worse, this affliction falls particularly hard on low-wage workers due to high cost of medical services. Thus, Chinese migrants with hypertension were less likely to report affordable medical expenses and services 
TABLE 1: Demographic characteristics among adults with hypertensive state, $N(\%)$.

\begin{tabular}{|c|c|c|c|c|c|}
\hline & Normal pressure & Prehypertension & MMS hypertension & chi2 & $p$ value \\
\hline Age & & & & $207.6162^{* * *}$ & 0.000 \\
\hline $9-25$ & $756(30.63)$ & $111(4.50)$ & $12(0.49)$ & & \\
\hline $26-40$ & $829(33.59)$ & $258(10.45)$ & $40(1.62)$ & & \\
\hline$\geq 41$ & $267(10.82)$ & $121(4.90)$ & $74(3.00)$ & & \\
\hline Gender & & & & $98.7121^{* * *}$ & 0.000 \\
\hline Male & $973(39.42)$ & $370(14.99)$ & $94(3.81)$ & & \\
\hline Female & $879(35.62)$ & $120(4.86)$ & $32(1.30)$ & & \\
\hline Marital status & & & & $126.4450^{* * *}$ & 0.000 \\
\hline Married & 967 (39.18) & $346(14.02)$ & $104(4.21)$ & & \\
\hline Remarried & $14(0.57)$ & $4(0.16)$ & $2(0.08)$ & & \\
\hline Cohabited & $21(0.85)$ & $0(0.00)$ & $0(0.00)$ & & \\
\hline Divorced & $32(1.30)$ & $11(0.45)$ & $2(0.08)$ & & \\
\hline Widowed & $9(0.36)$ & $5(0.20)$ & $5(0.20)$ & & \\
\hline Never married & 809 (32.78) & $124(5.02)$ & $13(0.53)$ & & \\
\hline Physical disabilities & & & & 0.9726 & 0.615 \\
\hline No & $1,781(72.16)$ & $467(18.92)$ & $122(4.94)$ & & \\
\hline Yes & $71(2.88)$ & $23(0.93)$ & $4(0.16)$ & & \\
\hline Sick injured & & & & 2.5501 & 0.279 \\
\hline No & $1,514(61.35)$ & $395(16.00)$ & $96(3.89)$ & & \\
\hline Yes & $338(13.70)$ & $95(3.85)$ & $30(1.22)$ & & \\
\hline Regular smoker & & & & $33.5242^{* * *}$ & 0.000 \\
\hline No & $1,369(55.47)$ & $303(12.28)$ & $77(3.12)$ & & \\
\hline Yes & $483(19.57)$ & $187(7.58)$ & 49 (1.99) & & \\
\hline Unaffordable expenses & & & & $8.3172^{* *}$ & 0.016 \\
\hline No & $1,835(74.35)$ & $478(19.37)$ & $123(4.98)$ & & \\
\hline Yes & $17(0.69)$ & $12(0.49)$ & $3(0.12)$ & & \\
\hline Unaffordable services & & & & $12.7682^{* * *}$ & 0.002 \\
\hline No & $1,715(69.49)$ & $429(17.38)$ & $115(4.66)$ & & \\
\hline Yes & $137(5.55)$ & $61(2.47)$ & $11(0.45)$ & & \\
\hline
\end{tabular}

which produced inadequate healthcare access. This study suggested that, even among those who afforded medical expenses and services, barriers to receiving affordable healthcare were still a challenge.

A possible explanation for the unaffordable expenses was due to lack of basic health insurance which dramatically increased the risk of depression based on northwestern Chinese community samples [17]. It is a common sense that mental disorders are risk factors for hypertension. China has achieved high population coverage rate over a short time period, starting with a limited benefit package. However, poor people have less benefit from New Cooperative Medical Scheme (NCMS) in terms of health service utilization [18]. The prices, availability, and affordability of medicines in China were not equitable access to basic medical treatments, especially for the poor [19]. Thus, psychiatric disorders produced by socioeconomic factors increased the risk of hypertension, when the migrants were out of the protection of social, health, and medical insurance.

Unaffordable medical care can be explained by marketization of health and social service organizations. The finding that a significantly higher proportion of married, employed, and women migrants aged 36 to 44 years had unaffordable medical care suggested that factors other than individual (such as employer) were also related to insurance status. Moreover, the insured still paid high amount of out-of-pocket medical expenditure [20]. NCMS improved the situation of receiving healthcare services but did not reduce the high healthcare fees [21]. The rapid increase of public funding to subsidize health insurance in China did not mitigate the out-of-pocket payment for healthcare over the past decade [22]. Thus, organizational, institutional, and employers' power dominate affordability, accessibility, and availability of Chinese migrants' healthcare.

This finding was consistent with those of earlier studies. For example, a study concluded that rural-urban migrant workers might well be left out of sharing the social and economic development [23]. Another study indicated that young migrant male workers appeared to be most vulnerable in their psychological well-being [24]. A published literature also argued that health systems governance was criticized as ineffective and inefficient in the development and operation 


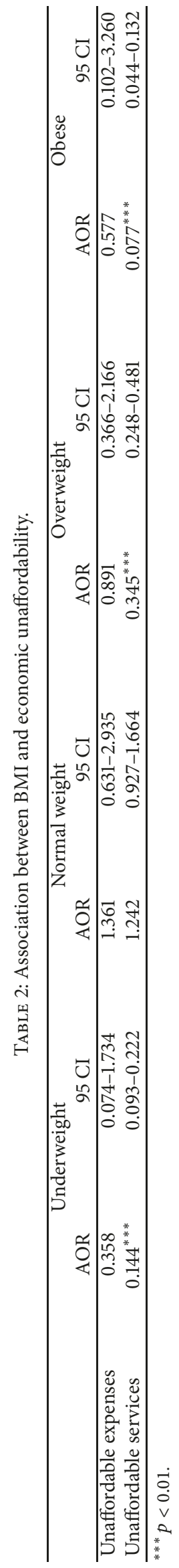




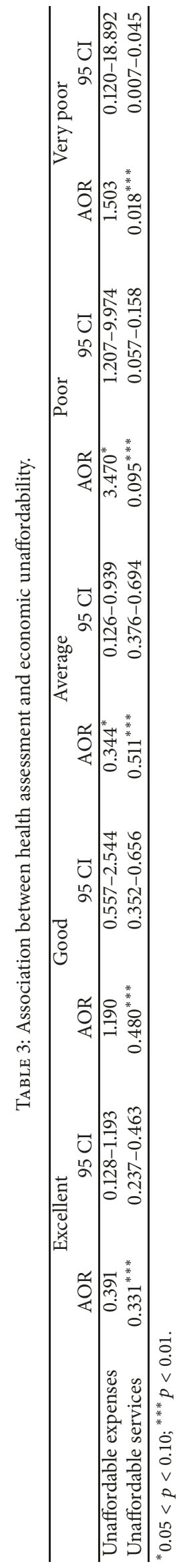


TABLE 4: Association between hypertensive states with economic unaffordability.

\begin{tabular}{|c|c|c|c|}
\hline & $\begin{array}{c}\text { Normal pressure } \\
\text { AOR }(95 \% \mathrm{CI})\end{array}$ & $\begin{array}{c}\text { Prehypertension } \\
\text { AOR }(95 \% \text { CI })\end{array}$ & $\begin{array}{c}\text { MMS hypertension } \\
\text { AOR }(95 \% \mathrm{CI})\end{array}$ \\
\hline \multicolumn{4}{|l|}{$\overline{\text { Age }}$} \\
\hline $9-25$ & 1.00 (reference) & 1.00 (reference) & 1.00 (reference) \\
\hline $26-40$ & $1.380^{* * *}(1.150-1.657)$ & $0.598^{* * *}(0.494-0.723)$ & $0.097^{* * *}(0.069-0.137)$ \\
\hline$\geq 41$ & $0.847(0.660-1.086)$ & $0.560^{* * *}(0.428-0.732)$ & $0.418^{* * *}(0.310-0.565)$ \\
\hline \multicolumn{4}{|l|}{ Gender } \\
\hline Male & 1.00 (reference) & 1.00 (reference) & 1.00 (reference) \\
\hline Female & $3.823^{* * *}(3.059-4.777)$ & $0.263^{* * *}(0.207-0.335)$ & $0.206^{* * *}(0.140-0.301)$ \\
\hline \multicolumn{4}{|l|}{ Marital status } \\
\hline Married & 1.00 (reference) & 1.00 (reference) & 1.00 (reference) \\
\hline Remarried & $0.874(0.301-2.542)$ & $0.918(0.286-2.945)$ & $1.586(0.325-7.747)$ \\
\hline Divorced & $1.103(0.574-2.121)$ & $1.028(0.535-1.974)$ & $0.430(0.085-2.169)$ \\
\hline Widowed & $0.473(0.162-1.378)$ & $1.226(0.379-3.968)$ & $2.589(0.740-9.052)$ \\
\hline Never married & $3.519^{* * *}(2.865-4.323)$ & $0.266^{* * *}(0.214-0.330)$ & $0.034^{* * *}(0.019-0.060)$ \\
\hline \multicolumn{4}{|c|}{ Physical disabilities } \\
\hline No & 1.00 (reference) & 1.00 (reference) & 1.00 (reference) \\
\hline Yes & $1.098(0.677-1.781)$ & $1.007(0.605-1.676)$ & $0.472(0.173-1.290)$ \\
\hline \multicolumn{4}{|l|}{ Sick injured } \\
\hline No & 1.00 (reference) & 1.00 (reference) & 1.00 (reference) \\
\hline Yes & $1.049(0.810-1.358)$ & $0.861(0.651-1.138)$ & $0.997(0.620-1.602)$ \\
\hline \multicolumn{4}{|c|}{ Regular Smokers } \\
\hline No & 1.00 (reference) & 1.00 (reference) & 1.00 (reference) \\
\hline Yes & $1.258^{*}(1.012-1.564)$ & $0.780^{*}(0.621-0.978)$ & $0.474^{* * *}(0.331-0.678)$ \\
\hline \multicolumn{4}{|c|}{ Unaffordable expenses } \\
\hline No & 1.00 (reference) & 1.00 (reference) & 1.00 (reference) \\
\hline Yes & $0.595(0.246-1.436)$ & $1.710(0.703-4.156)$ & $1.800(0.402-8.064)$ \\
\hline \multicolumn{4}{|c|}{ Unaffordable services } \\
\hline No & 1.00 (reference) & 1.00 (reference) & 1.00 (reference) \\
\hline Yes & $0.659^{*}(0.462-0.940)$ & $1.672^{* *}(1.153-2.425)$ & $0.588(0.274-1.263)$ \\
\hline
\end{tabular}

of Cooperative Medical Scheme and New Rural Cooperative Medical Scheme [25]. Thereby, poor connection between urban and rural insurance system was partially responsible for the omission of the migrants' health support plans.

Together, these findings show that the healthcare system should seek to reduce the barriers for these patients to achieve BP control. Enrolled in the Urban Employee Basic Health Insurance scheme, people with hypertension in Shanghai, China, had no access to publicity of hypertension prevention knowledge [26]. For the floating population, health insurance coverage needs to be improved [27]. The fragmented health insurance schemes generated inequitable healthcare utilization and health outcomes for the elderly [28]. In order to effectively control hypertension, a study highlighted better health insurance packages [29]. These findings may encourage employment service agencies to expand the coverage of health service from a specific targeted population to general population included migrants.

This finding was in line with the previous research that unaffordable expenses, unaffordable insurance, and unaffordable services were related to income inequality. Based on the China Health and Nutrition Survey (1991-2006), health disparities in China were related to rising income inequality and in particular to the adverse health and income experience of older (wo)men [30]. Based on US data from four waves of the Panel Study of Income Dynamics, low wages were risk factors for hypertension among working people for women and persons aged 25-44 years [31]. Comparing 2009 with 2006 , the income inequality in health insurance coverage was largely corrected in China through rapid expansion in rural areas and initiation of urban resident basic medical insurance in urban areas [32]. This combination of findings provided some support for the intuition that income inequality caused by poor distribution of wealth resources led to health vulnerabilities of the marginalized persons.

This study had several limitations. First, all hypertension information collected from the RUMiC was from measurement of systolic pressure and diastolic pressure. In fact, most of the Chinese migrants with hypertension were unaware of the condition, leading to under-reporting of barriers to care in this population. In addition, Chinese migrants with hypertension were unaware of blood control. Second, the 
RUMiC did not provide information on antihypertensive care and cure. Thus, the expenditure of antihypertensive cure and hypertension affordability could not be assessed and estimated scientifically. Third, the survey provided no information about the affordable medical expenditure as a proportion of household income. Thus, a method of more accurate unaffordable measure could not be conducted. Finally, given that only 15 cities were surveyed, the data may not be nationally representative.

\section{Conclusion}

In conclusion, the hypertensive states were serious in the Chinese migrants. There were significant differences between hypertensive states among the migrants with respect to affordable and unaffordable medical expenses and services. Also, part of Chinese migrants with hypertension was likely to report unaffordable care under the condition that there were significant differences between hypertensive states among the migrants with respect to specific sociodemographic factors. Among the Chinese migrants, economic unaffordability was associated with abnormal weight, poor health status, and hypertensive states. Subsequently, some policies and interventions suggested were highlighted.

\section{Data Availability}

The 2009 RUMiC data used to support the findings of this study are available at http://idsc.iza.org/rumic.

\section{Conflicts of Interest}

The author declares that they have no conflicts of interest.

\section{References}

[1] J. Wang, L. Zhang, F. Wang, L. Liu, and H. Wang, "Prevalence, awareness, treatment, and control of hypertension in China: results from a national survey," American Journal of Hypertension, vol. 27, no. 11, pp. 1355-1361, 2014.

[2] Y. Gao, G. Chen, H. Tian et al., "Prevalence of hypertension in China: a cross-sectional study," PLoS ONE, vol. 8, no. 6, Article ID e65938, 2013.

[3] X. Wang, M. L. Bots, F. Yang, A. W. Hoes, and I. Vaartjes, "Prevalence of hypertension in China: A systematic review andmeta-regression analysis of trends and regional differences," Journal of Hypertension, vol. 32, no. 10, pp. 1919-1927, 2014.

[4] Y. Liang, R. Liu, S. Du, and C. Qiu, “Trends in incidence of hypertension in Chinese adults, 1991-2009: the China Health and Nutrition Survey," International Journal of Cardiology, vol. 175, no. 1, pp. 96-101, 2014.

[5] C. Dong, P. Ge, X. Ren, H. Fan, and X. Yan, "Prevalence, awareness, treatment and control of hypertension among adults in rural north-western China: A cross-sectional population survey," Journal of International Medical Research, vol. 41, no. 4, pp. 1291-1300, 2013.

[6] X. Chen, W. Wei, S. Zou et al., "Trends in the prevalence of hypertension in island and coastal areas of China: a systematic review with meta-analysis," American Journal of Hypertension, vol. 27, no. 12, pp. 1503-1510, 2014.
[7] Y.-B. Wang, D.-G. Kong, L.-L. Ma, and L.-X. Wang, "Patient related factors for optimal blood pressure control in patients with hypertension," African Health Sciences, vol. 13, no. 3, pp. 579-583, 2013.

[8] X. L. Feng, M. Pang, and J. Beard, "Health system strengthening and hypertension awareness, treatment and control: data from the China Health and Retirement Longitudinal Study," Bulletin of the World Health Organization, vol. 92, no. 1, pp. 29-41, 2014.

[9] K. K. F. Lam and J. M. Johnston, "Health insurance and healthcare utilisation for Shenzhen residents: A tale of registrants and migrants?" BMC Public Health, vol. 12, no. 1, article no. 868, 2012.

[10] A. V. Chobanian, G. L. Bakris, H. R. Black et al., "The seventh report of the joint national committee on prevention, detection, evaluation, and treatment of high blood pressure: the JNC 7 report," The Journal of the American Medical Association, vol. 289, no. 19, pp. 2560-2572, 2003.

[11] C. Tripolino, A. Gnasso, C. Carallo, F. B. Scavelli, and C. Irace, "Hemorheological profiles of subjects with prehypertension," Hypertension Research, vol. 39, no. 7, pp. 519-523, 2016.

[12] W. J. Elliott and H. R. Black, "Prehypertension," Nature Clinical Practice Cardiovascular Medicine, vol. 4, no. 10, pp. 538-548, 2007.

[13] G. Mancia, G. de Backer, and A. Dominiczak, "2007 Guidelines for the Management of Arterial Hypertension: The Task Force for the Management of Arterial Hypertension of the European Society of Hypertension (ESH) and of the European Society of Cardiology (ESC)," Journal of Hypertension, vol. 25, no. 6, pp. 1105-1187, 2007.

[14] H. Li, X. Wei, M. C. Wong et al., "A comparison of the quality of hypertension management in primary care between Shanghai and Shenzhen: A cohort study of 3196 patients," Medicine (United States), vol. 94, no. 5, p. e455, 2015.

[15] Y. Jin, Z. Hou, and D. Zhang, "Determinants of health insurance coverage among people aged 45 and over in China: Who buys public, private and multiple insurance," PLoS ONE, vol. 11, no. 8, Article ID e0161774, 2016.

[16] Ministry of Health of the People's Republic of China, The guidelines for prevention and control of overweight and obesity in Chinese adults, People's Medical Publishing House, 2006.

[17] D. Tian, Z. Qu, X. Wang et al., "The role of basic health insurance on depression: An epidemiological cohort study of a randomized community sample in Northwest China," BMC Psychiatry, vol. 12, article no. 151, 2012.

[18] X. Liu, S. Tang, B. Yu et al., "Can rural health insurance improve equity in health care utilization? a comparison between China and Vietnam," International Journal for Equity in Health, vol. 11, no. 1, article no. 10, 2012.

[19] M. Jiang, S. Yang, K. Yan, J. Liu, J. Zhao, and Y. Fang, "Measuring Access to Medicines: A Survey of Prices, Availability and Affordability in Shaanxi Province of China," PLoS ONE, vol. 8, no. 8, Article ID e70836, 2013.

[20] Y. Wang, Y. Jiang, Y. Li, X. Wang, C. Ma, and S. Ma, "Health insurance utilization and its impact: Observations from the middle-aged and elderly in China," PLoS ONE, vol. 8, no. 12, Article ID e80978, 2013.

[21] X. Wang, X. He, A. Zheng, and X. Ji, “The effects of China's New Cooperative Medical Scheme on accessibility and affordability of healthcare services: an empirical research in Liaoning Province," BMC Health Services Research, vol. 14, no. 1, 2014.

[22] Q. Long, L. Xu, H. Bekedam, and S. Tang, "Changes in health expenditures in China in 2000s: Has the health system reform 
improved affordability," International Journal for Equity in Health, vol. 12, no. 1, article no. 40, 2013.

[23] L. Xu, Y. Wang, C. D. Collins, and S. Tang, "Urban health insurance reform and coverage in China using data from National Health Services Surveys in 1998 and 2003," BMC Health Services Research, vol. 7, article no. 37, 2007.

[24] Z. Zeng, Y. Guo, L. Lu, L. Han, W. Chen, and L. Ling, "Mental health status and work environment among workers in smalland medium-sized enterprises in Guangdong, China - A crosssectional survey," BMC Public Health, vol. 14, article no. 1162, 2014.

[25] B. Yuan, W. Jian, L. He, B. Wang, and D. Balabanova, "The role of health system governance in strengthening the rural health insurance system in China," International Journal for Equity in Health, vol. 16, no. 1, article no. 44, 2017.

[26] X. Zhang, Y. Zhang, X. Xiao, X. Ma, and J. He, “The relation between health insurance and management of hypertension in Shanghai, China: A cross-sectional study," BMC Public Health, vol. 16, no. 1, article no. 959, 2016.

[27] Y. Zhao, B. Kang, Y. Liu et al., "Health insurance coverage and its impact on medical cost: Observations from the floating population in China el11555," PLoS ONE, vol. 9, no. 11, Article ID el11555, 2014.

[28] X. Liu, H. Wong, and K. Liu, "Outcome-based health equity across different social health insurance schemes for the elderly in China," BMC Health Services Research, vol. 16, no. 1, article no. 1261, 2016.

[29] Y. Liao, S. Gilmour, and K. Shibuya, "Health insurance coverage and hypertension control in China: Results from the China health and nutrition survey," PLoS ONE, vol. 11, no. 3, Article ID e0152091, 2016.

[30] S. Baeten, T. Van Ourti, and E. van Doorslaer, "Rising inequalities in income and health in China: Who is left behind?" Journal of Health Economics, vol. 32, no. 6, pp. 1214-1229, 2013.

[31] J. P. Leigh and J. Du, "Are low wages risk factors for hypertension?" European Journal of Public Health, vol. 22, no. 6, pp. 854859, 2012.

[32] J. Liu, L. Shi, Q. Meng, and M. M. Khan, "Income-related inequality in health insurance coverage: Analysis of China Health and Nutrition Survey of 2006 and 2009," International Journal for Equity in Health, vol. 11, no. 1, article no. 42, 2012. 


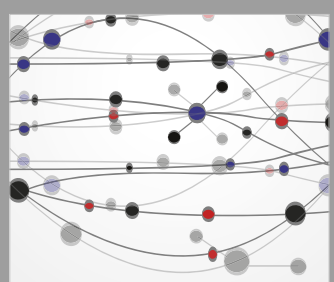

The Scientific World Journal
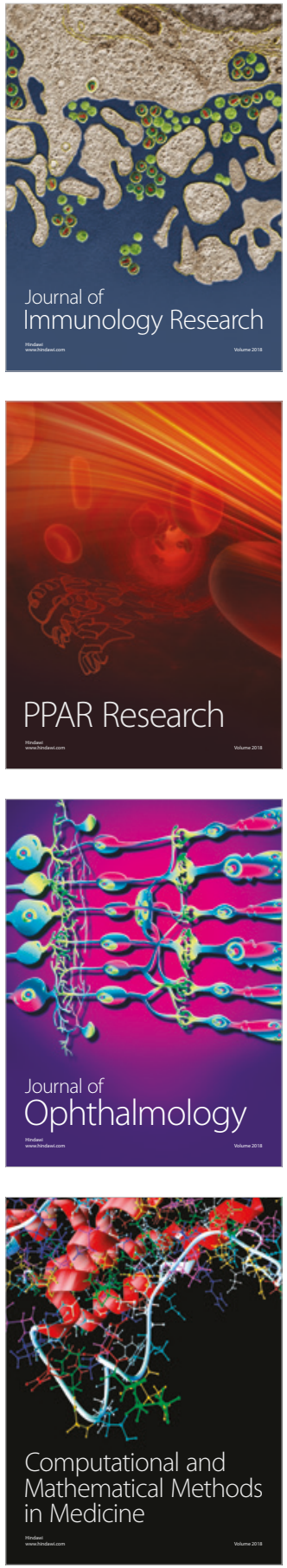

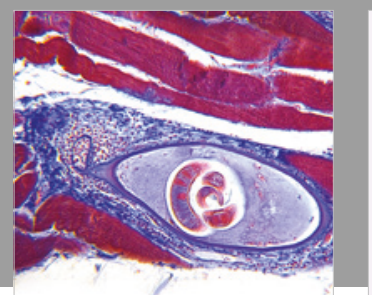

Gastroenterology Research and Practice

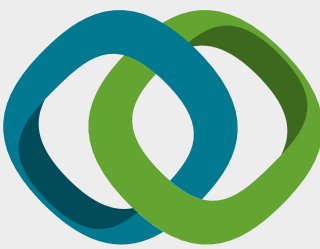

\section{Hindawi}

Submit your manuscripts at

www.hindawi.com
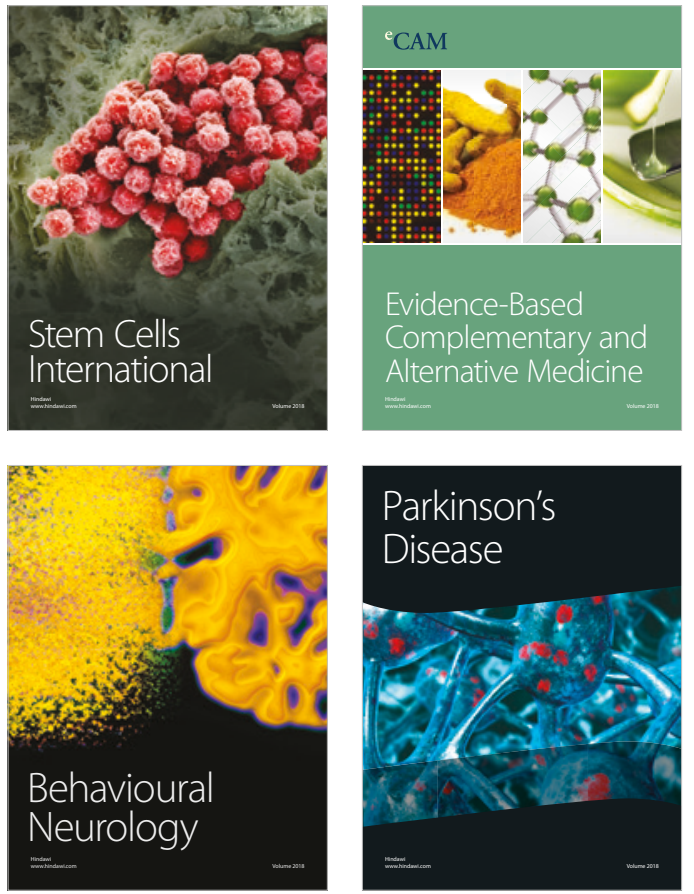

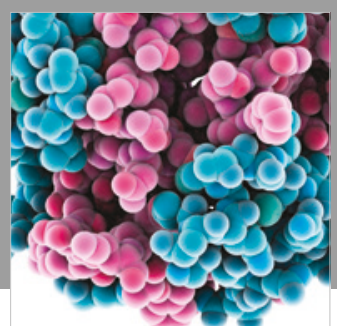

ournal of

Diabetes Research

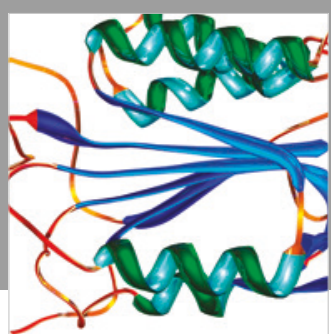

Disease Markers
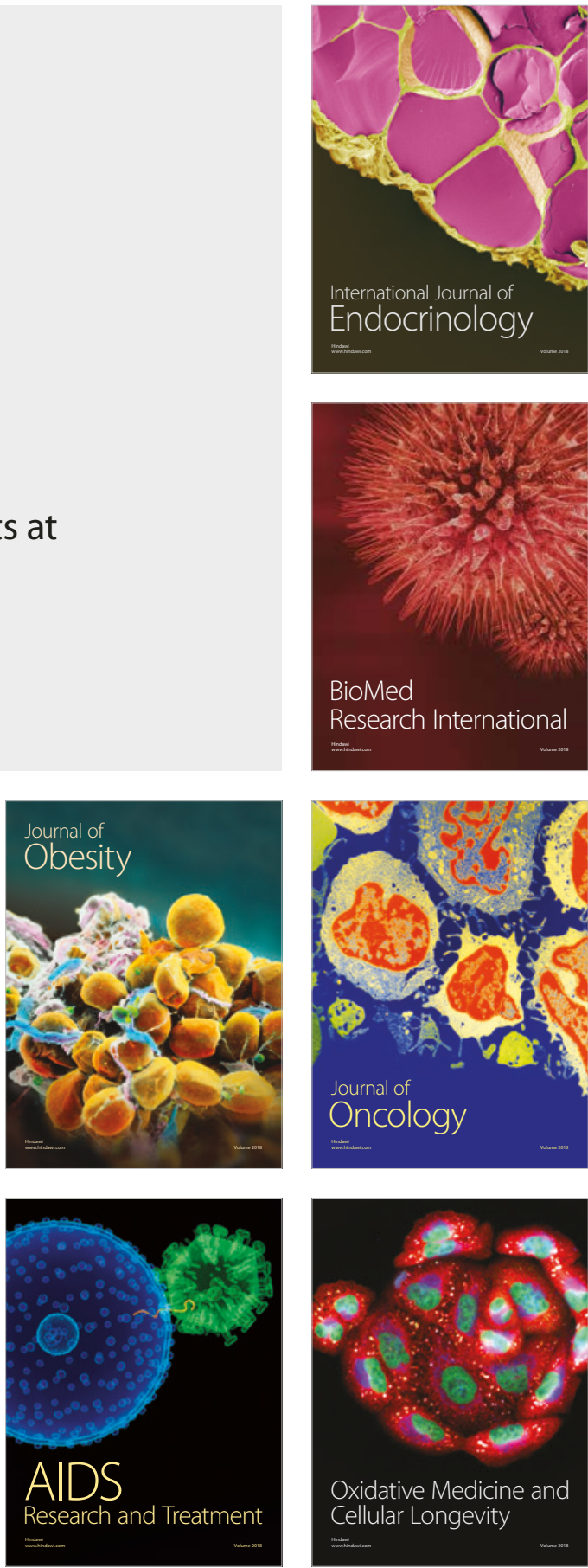